\title{
Preparation and cytotoxicity of a novel carbon nano-onion platinum nanomaterial for potential cancer therapy
}

Cammie York, Tiffany Koba \& Dr. Joseph E. Bradshaw

Ouachita Baptist University Department of Chemistry, Arkadelphia, AR 71998-0001

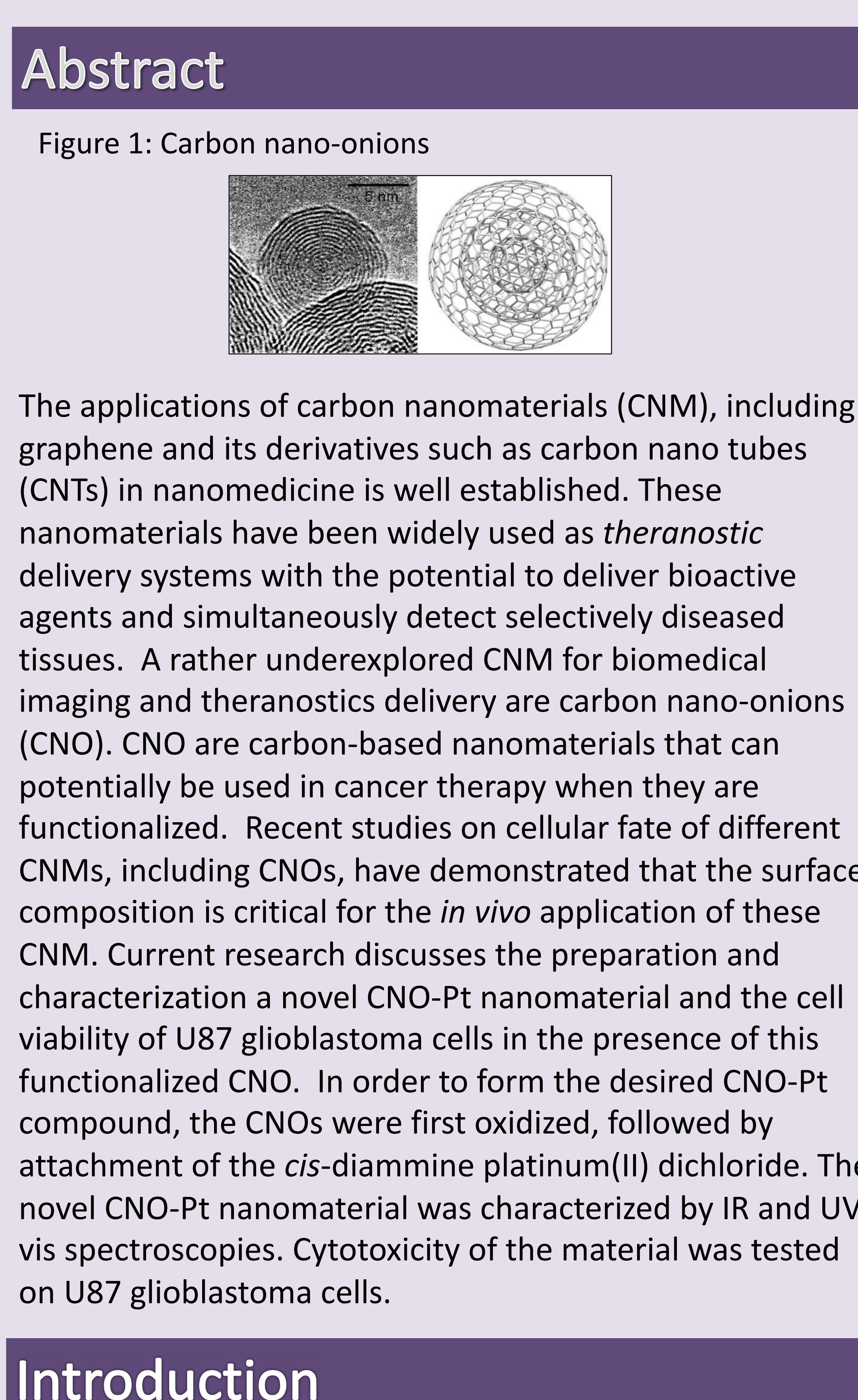

Introduction

\section{U87 Cell Line}

- N 20,000 Americans are diagnosed with a glioma each year Glioma tumors sprout and spread quickly in the brain - More than 50\% die within 18 months

- Very low survival rate

\section{Carbon Nano-onions}

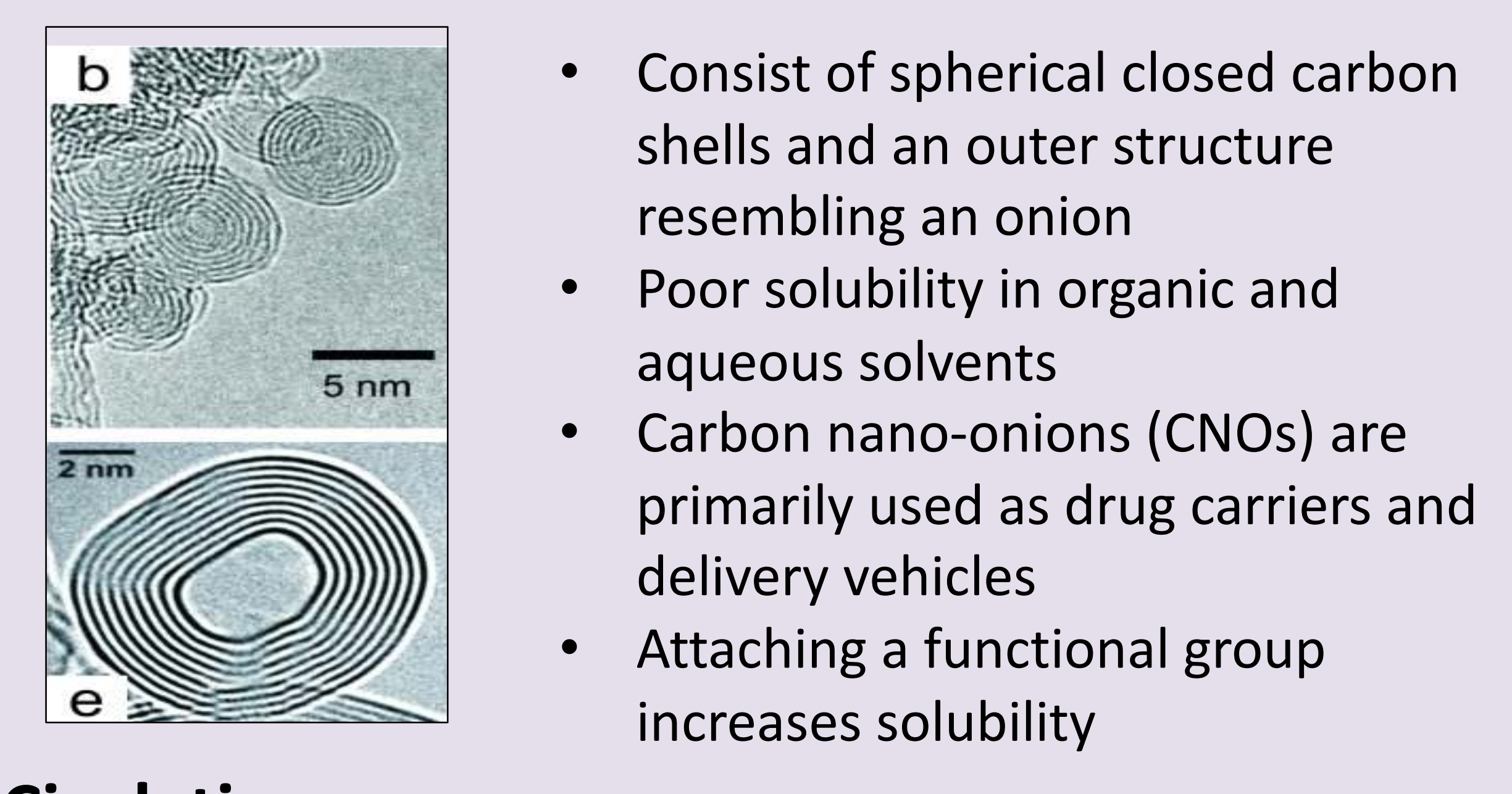

Cisplatin

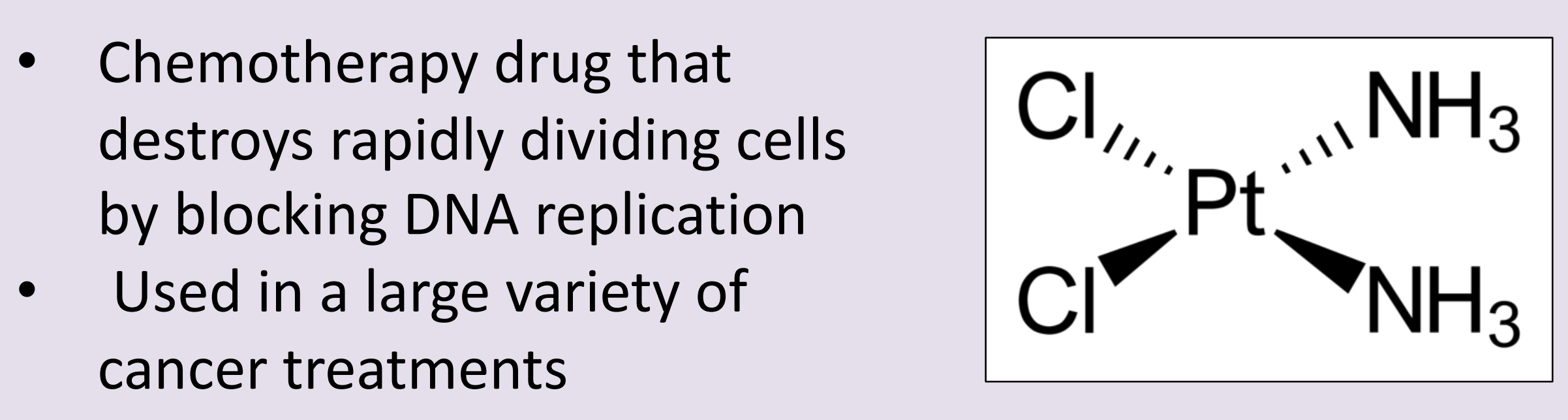

\section{Preparation}

Reaction 1

- $\mathrm{CNOs}$ refluxed in $3 \mathrm{M}$ nitric acid to form oxidized-CNOs

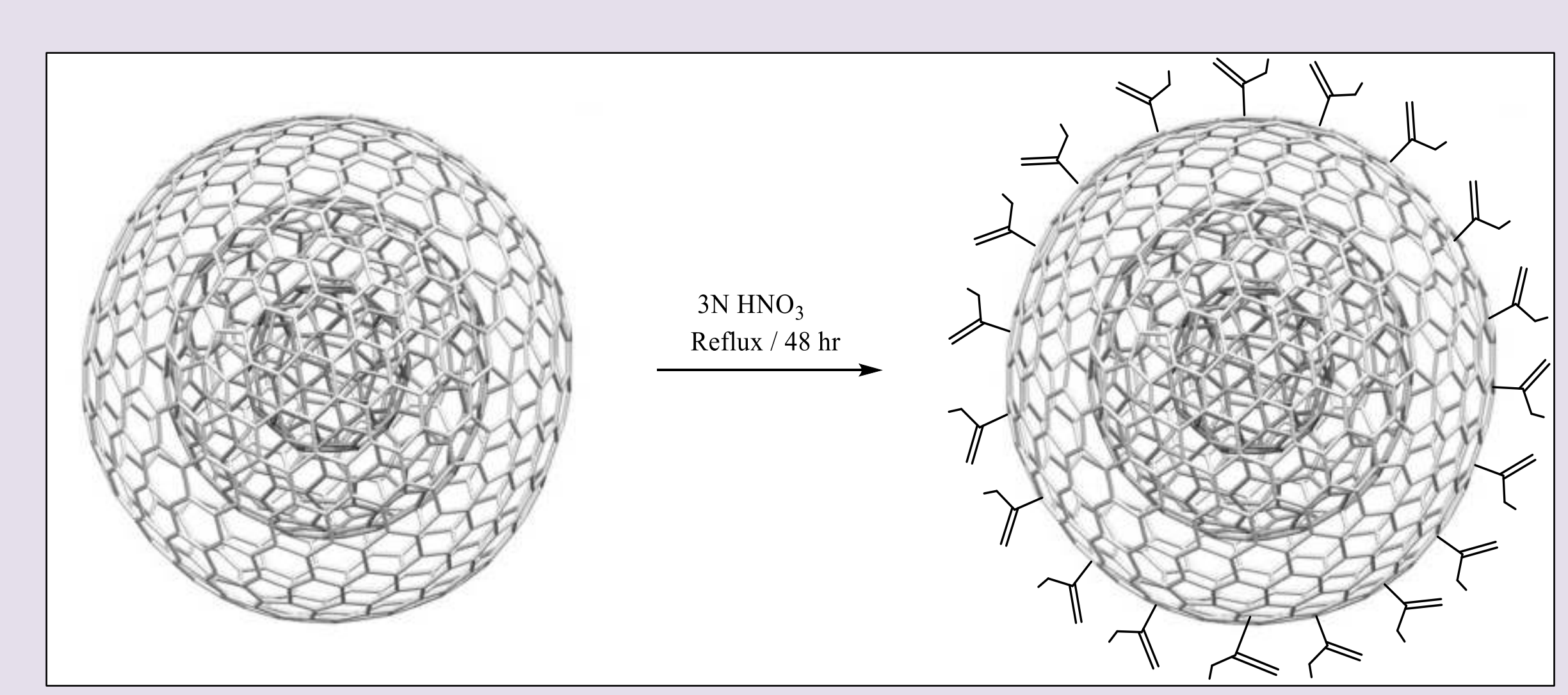

Reaction 2

Oxidized-CNOs and fluoresceinamine refluxed in DMF/THF to form fluorescent-CNOs

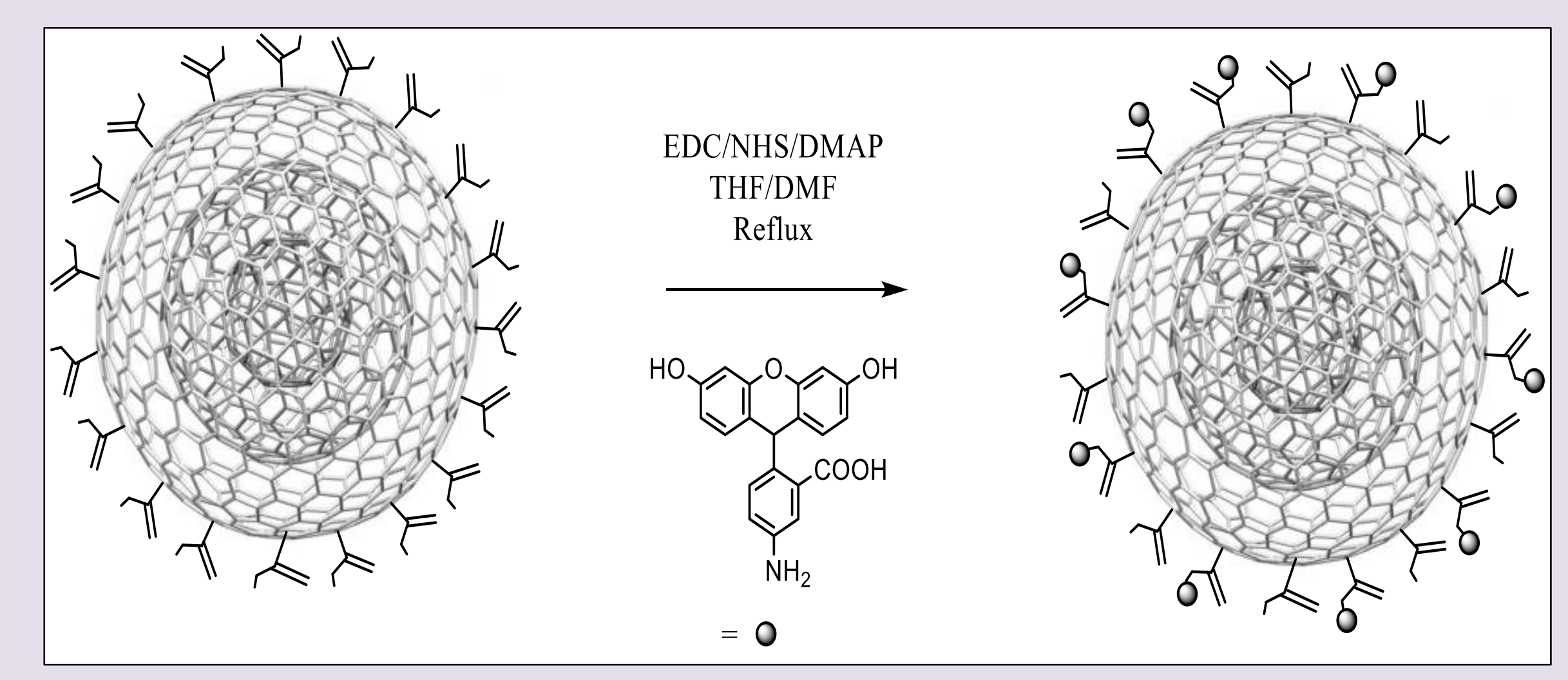

Reaction 3

- Oxidized-CNOs and cisplatin refluxed in DMF/THF
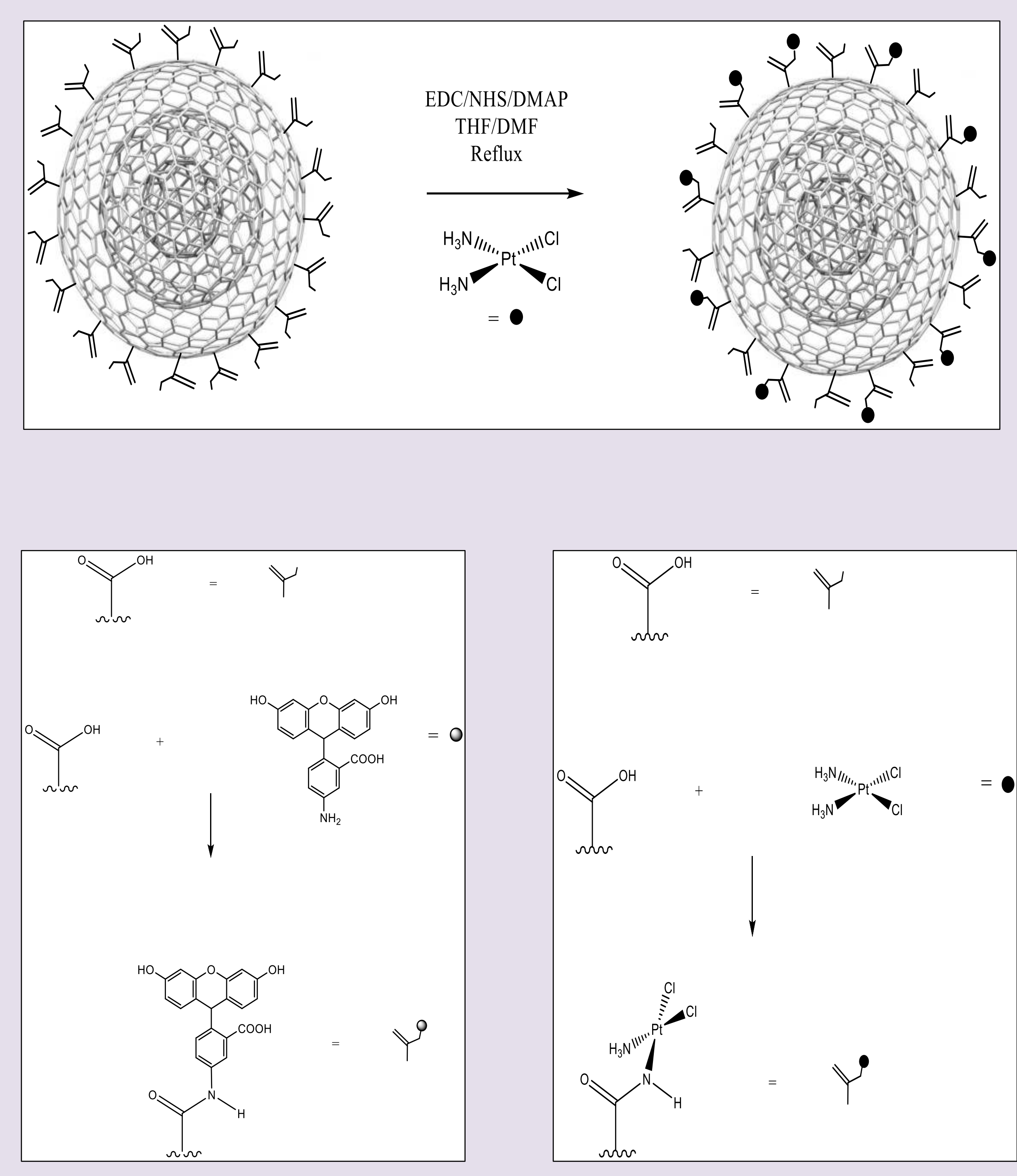

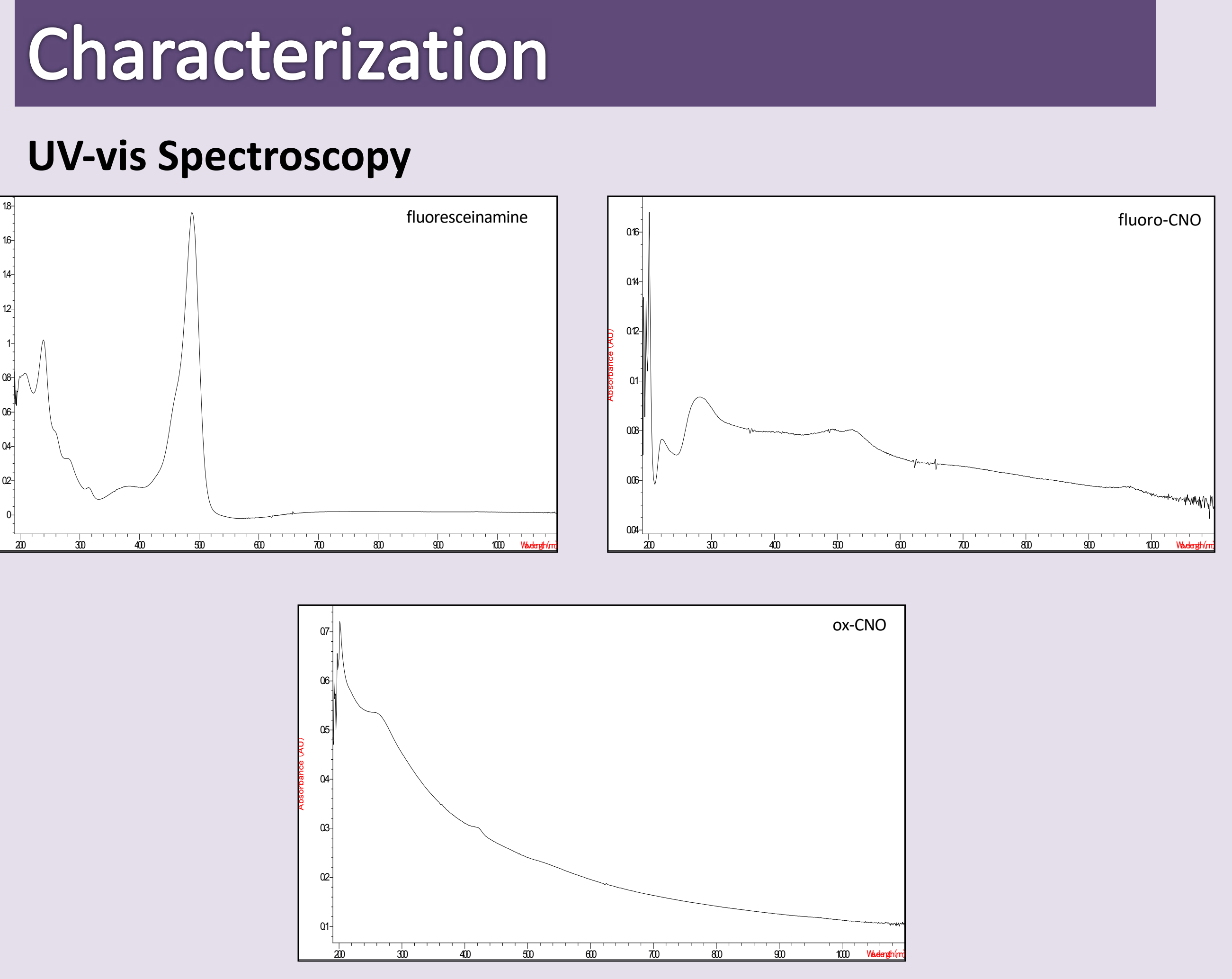

Infrared Spectroscopy
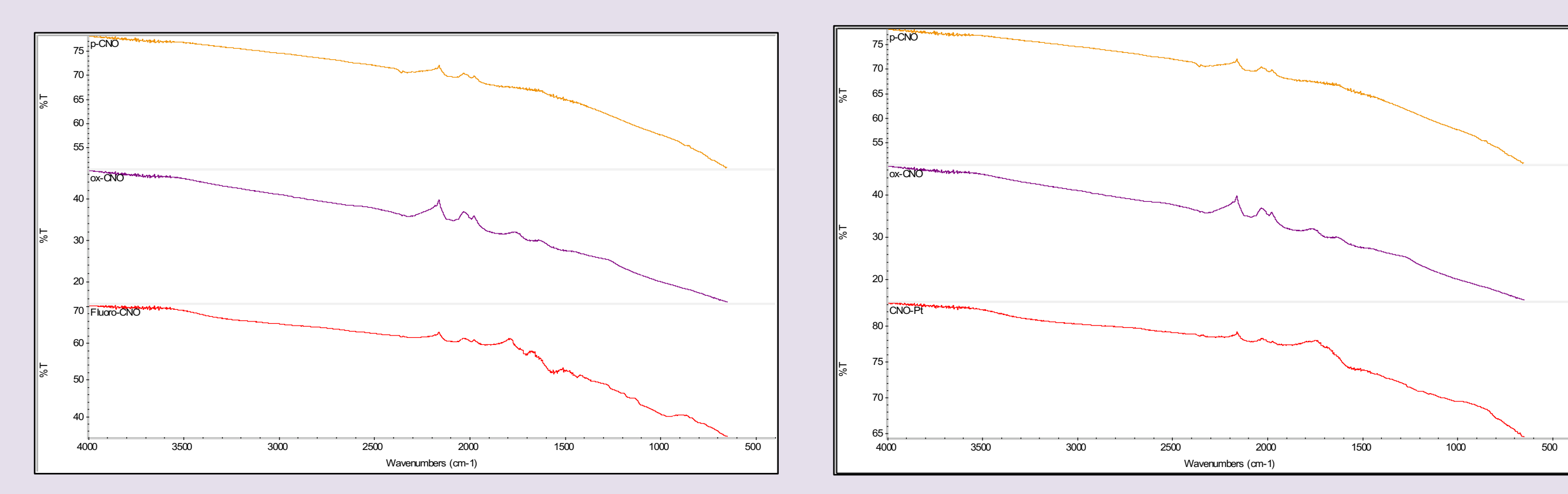

Fluorescence Microscopy

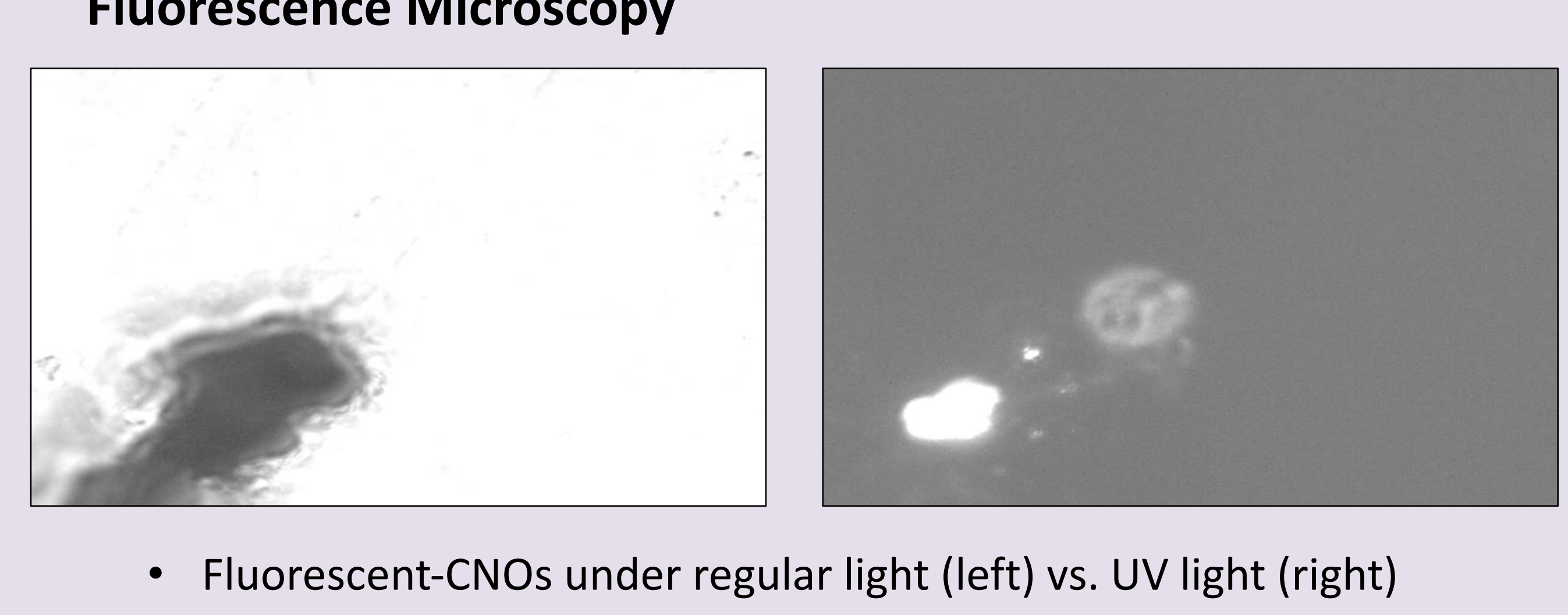

In-vitro Cytotoxicity Assay

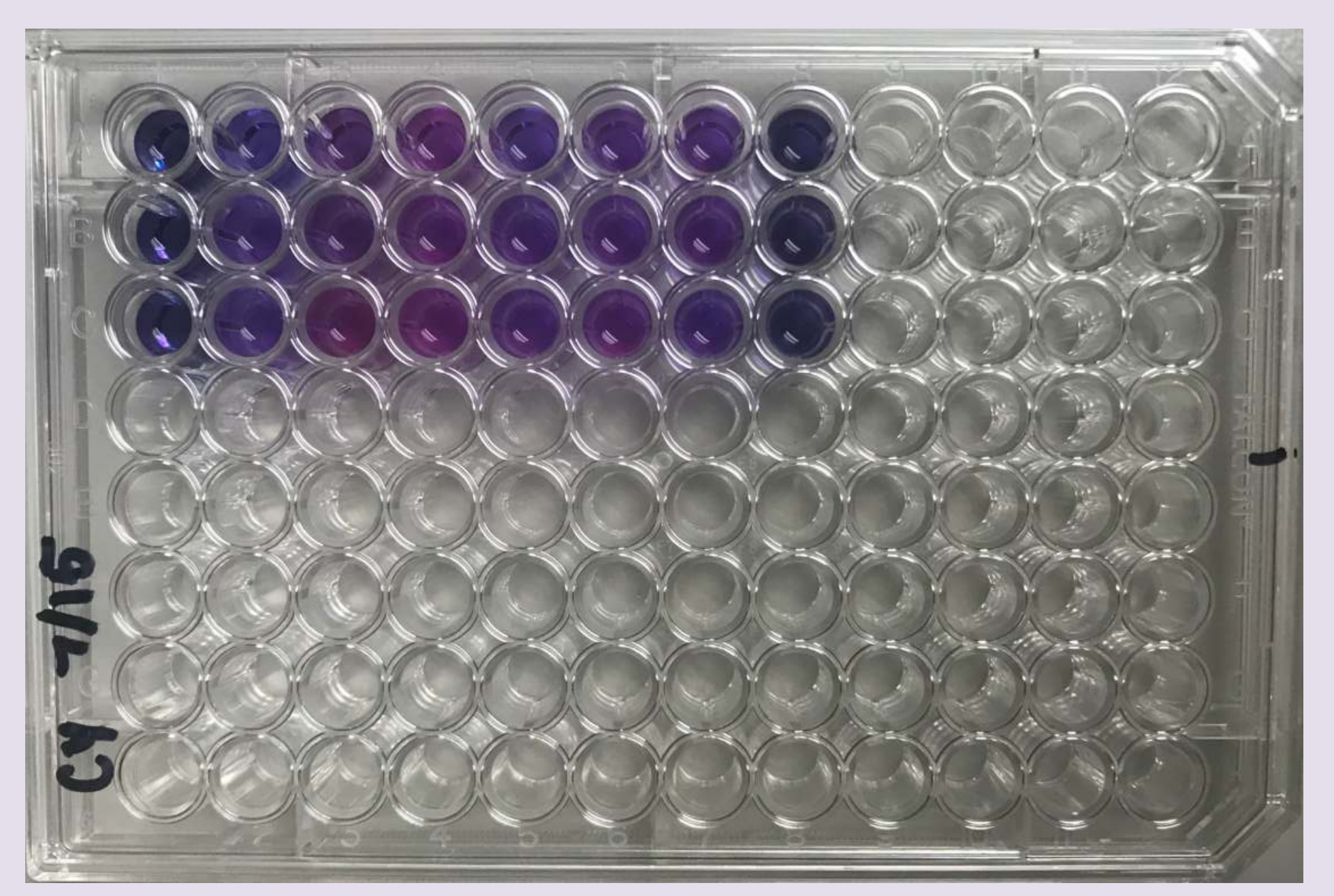

- Cells were exposed to oxidized-CNOs and fluorescentCNOs at concentrations of $10 \mathrm{ug} / \mathrm{mL}$

- Cells were exposed to cisplatin-CNO concentrations of $10 \mathrm{ug} / \mathrm{mL}, 5 \mathrm{ug} / \mathrm{mL}$, and $1 \mathrm{ug} / \mathrm{mL}$
Results
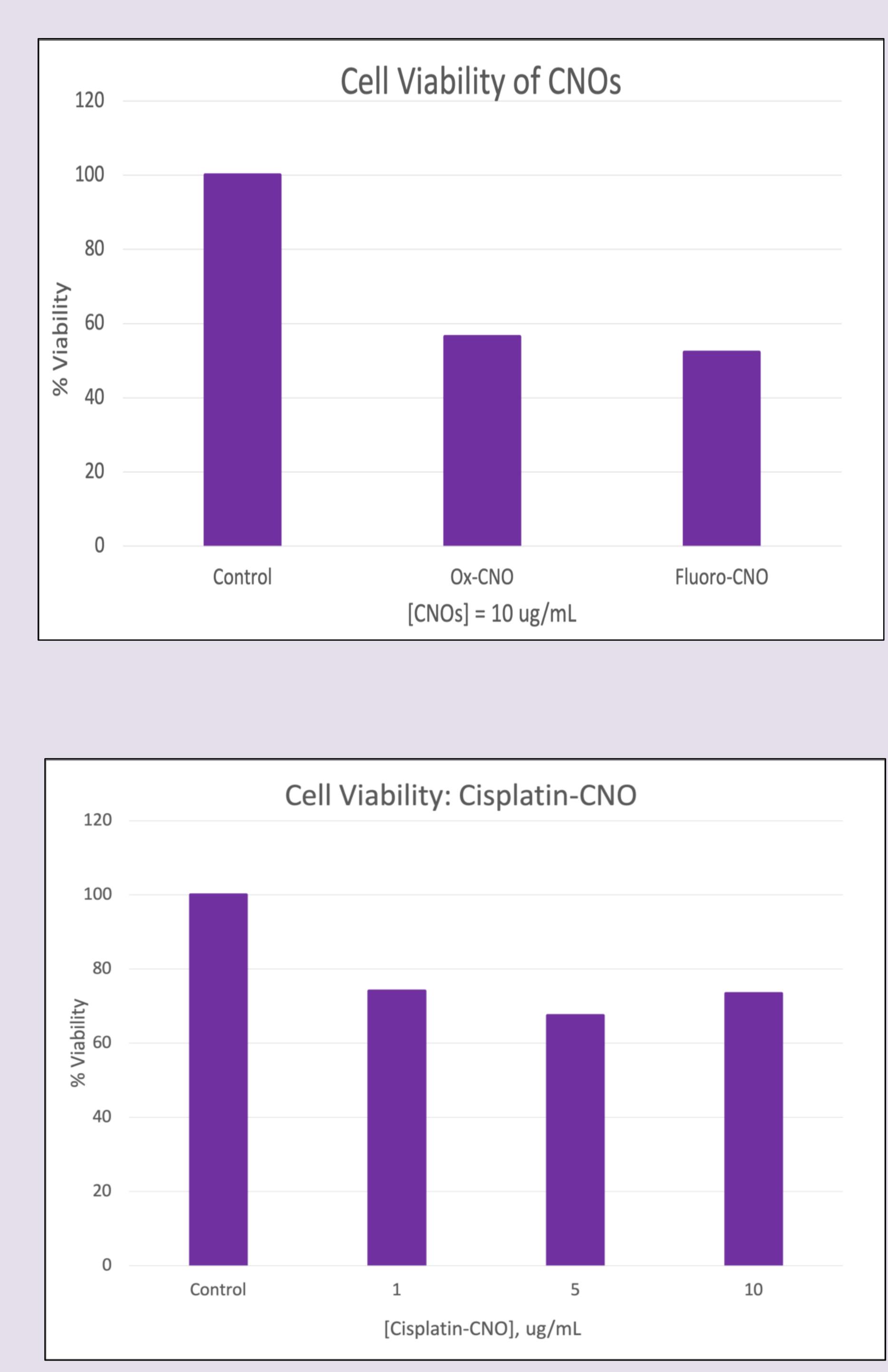

The in-vitro Cytotoxicity Assay indicates that percent cell viability decreased at all

concentrations of the cisplatin-CNO to oxidizd-CNOs and flued when exposed to oxidized-CNOs and fluorescent-CNOs

\section{Conclusions}

- A novel carbon nano-onion platinum material was prepared successfully.

cterized by UV-Vis and IR spectroscopies.

The spectrums confirm that the correct product was actually formed.

that cell viability decreased at all concentrations

\section{Future Direction}

- Pt determination using AA/ICP

- Perform MTT Assay on cells with a greater range of concentrations

- Examine cytotoxicity of cisplatin-CNOs on normal cells and other cancer cell lines

\section{Acknowledgements}

- Dr. J. D. Patterson Summer Research Program - Dr. Nathan Reyna

- Keller Smith

- Ouachita Baptist University 